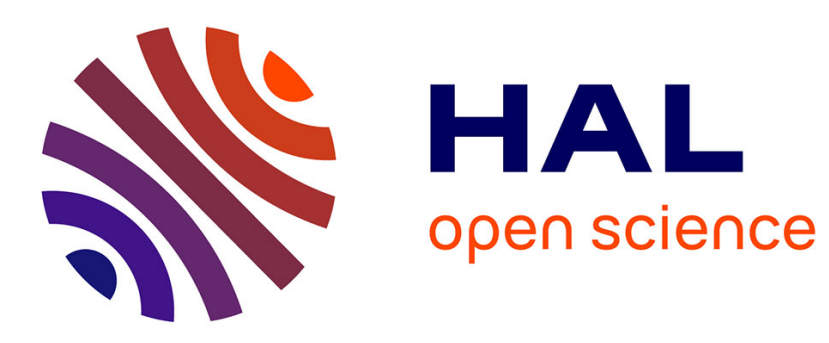

\title{
Boucle de ceinture en bronze doré (fin XIIIe - début XIVe siècle)
}

Jean-Pierre Pelletier, Lucy Vallauri

\section{To cite this version:}

Jean-Pierre Pelletier, Lucy Vallauri. Boucle de ceinture en bronze doré (fin XIIIe - début XIVe siècle). Archéologie du Midi Médiéval, 1997, 15-16, pp.324-325. 10.3406/amime.1997.1344 • halshs-01383149

\section{HAL Id: halshs-01383149 \\ https://shs.hal.science/halshs-01383149}

Submitted on 18 Oct 2016

HAL is a multi-disciplinary open access archive for the deposit and dissemination of scientific research documents, whether they are published or not. The documents may come from teaching and research institutions in France or abroad, or from public or private research centers.
L'archive ouverte pluridisciplinaire HAL, est destinée au dépôt et à la diffusion de documents scientifiques de niveau recherche, publiés ou non, émanant des établissements d'enseignement et de recherche français ou étrangers, des laboratoires publics ou privés. 


\section{Boucle de ceinture en bronze doré (fin XIIle - début XIVe siècle)}

In: Archéologie du Midi médiéval. Tome 15-16, 1997. pp. 324-325.

Citer ce document / Cite this document :

Pelletier Jean-Pierre. Boucle de ceinture en bronze doré (fin XIIle - début XIVe siècle). In: Archéologie du Midi médiéval. Tome 15-16, 1997. pp. 324-325.

doi : $10.3406 /$ amime.1997.1344

http://www.persee.fr/web/revues/home/prescript/article/amime_0758-7708_1997_num_15_1_1344 
forniment et arnes dejus scrit fo liurat per lodit honrat procurador an G. Amarell, obrer major deldit castell, per la forma que saguex.

110 - Primerament aymines de mill

Mardi 26 avril 1373, Ermengau Marti, procureur royal, commença de recevoir l'inventaire de G. Amarell, de la ville de Perpignan, maître des œuvres du château de la ville, des armes et équipements et des vivres qui sont dans le château et détaillé comme suit :

(...)

32 - Une grande caisse contenant 20 amynes de fèves 1

33 - Une autre grande caisse pleine de biscuits faits avec 14 livres de vieille farine qui était dans le château et qui date de 8 ans et qui ne vaut rien

(...)

Vivres du château

Réception faites par G. Amarell de Jean Vola, autrefois procureur royal, des choses ci-dessous, qui sont dans le château de Perpignan et pour son approvisionnement.

77 - D'abord il a reçu dudit Jean Vola des choses qui ont été apportées au château au mois de juillet 1362 : aymines $(29 \mathrm{~kg} 370 \mathrm{~g})$ de froment $\quad 72.000$ 78 - Plus aymines de farine $\quad 27.000$ 79 - Aymines d'orge 200

80 - De plus, au 27 août de la même année, aymines de froment

81- Vin pour approvisionnement, saumées

(saumade $=120 \mathrm{l}$ )

83 - Viande salée, contenant quintaux

(quintal $=40 \mathrm{~kg}$ )

85 - De plus, en 1365, aymines de seigle, de Berenger Ysern

86 - De plus, de Jean Vola, saumées de sel contenant en aymines de sel

Les réceptions faites par G. Amarell, maître des œuvres du château de Perpignan, de l'honorable G. Comes, autrefois procureur royal, des choses ci-dessous pour l'approvisionnement du château.

87 - D'abord G. Amarell a reçu et a mis dans ledit château le 25 septembre 1362, aymines de fèves 20

88- Aulx en tresse, quintaux

4

91- Pour fourniture du château, saumées de vinaigre 48

92- Pois chiches, aymines

2

98 - Aymines de froment de P. Blan

97

99 - 13 septembre 1363 aymines de millet de P. Blan, pour fourniture du château

Réception des vivres dessusdits, G. Amarell a remis audit Jean Vola, les fournitures ci-dessous, qui ont été enlevées du château.

100 - D'abord, G. Amarell livre à Jean Vola, aymines de froment

101 - Aymines d'orge livrées

Les approvisionnements ci-dessous furent mis au château de Perpignan, le 27 juillet 1374, par l'honorable
Armengau Marti, procureur royal, reçu par G. Amarell, maîtres des œuvres du château. Sous la forme suivante. 102 - D'abord, fut livré à $G$. Amarell, aymines de froment, de Bérenger Ysern pour le procureur $\quad 88$ 103 - Porc salé, de Jean Bages, boucher, 15 quintaux de 8 livres, à 4 florins par quinteaux

Les fournitures ci-dessous, furent mises dans le château de Perpignan le 25 mars 1376, par l'honorable Berenger de Margarola, procureur royal, ces approvisionnements et équipements ci-dessous furent livrés par l'honorable procureur à G. Amarell, maître des œuvres du château, sous la forme suivante.

110 - D'abord, aymines de millet

100

\section{BOUCHES-DU-RHONE}

\section{BOUCLES DE CEINTURE EN BRONZE DORÉ (FIN XIIIe - DÉBUT XIVe S.)}

\section{Jean-Pierre Pelletier, Lucy Vallauri*}

Deux boucles de ceinture de type analogue découvertes fortuitement dans les Bouches-du-Rhône nous ont été confiées pour examen par leurs inventeurs, tous deux archéologues : la première au cours de prospections dans la plaine de la Crau près d'Eyguières par Michel Poguet, et la seconde par Sébastien Favre lors d'une promenade, au bord de la route du Tholonet, près d'Aix-en-Provence.

Celle d'Eyguières est complète (long. $8 \mathrm{~cm}$, larg. 5,2 $\mathrm{cm})$. Elle se compose d'une boucle rectangulaire en bronze massif munie d'un ardillon, sur laquelle s'articule une chape presque carrée, en tôle de bronze, repliée autour de l'axe, avec encore les six rivets en bronze à tête bouletée pour la fixation sur le cuir de la ceinture. Le décor finement incisé est rehaussé d'or ; sur la traverse plate, c'est une bande de losanges soulignés par des remplissages de petits oculi réalisés à l'emporte-pièce ; sur la chape un motif quadrilobé décoré suivant le même principe est cantonné dans une bordure incisée en zigzags obtenus par le déplacement rapide du ciseau.

De la boucle aixoise, de forme et facture comparables, il ne subsiste que la traverse, un peu plus large $(6,2 \mathrm{~cm})$, ornée d'un motif entrelacé exécuté plus maladroitement.

Malgré l'absence de contexte archéologique, ces pièces parvenues dans un état assez exceptionnel sont

(*) Laboratoire d’Archéologie Médiévale Méditerranéenne, C.N.R.S., UMR 6572, Aix-en-Provence. 

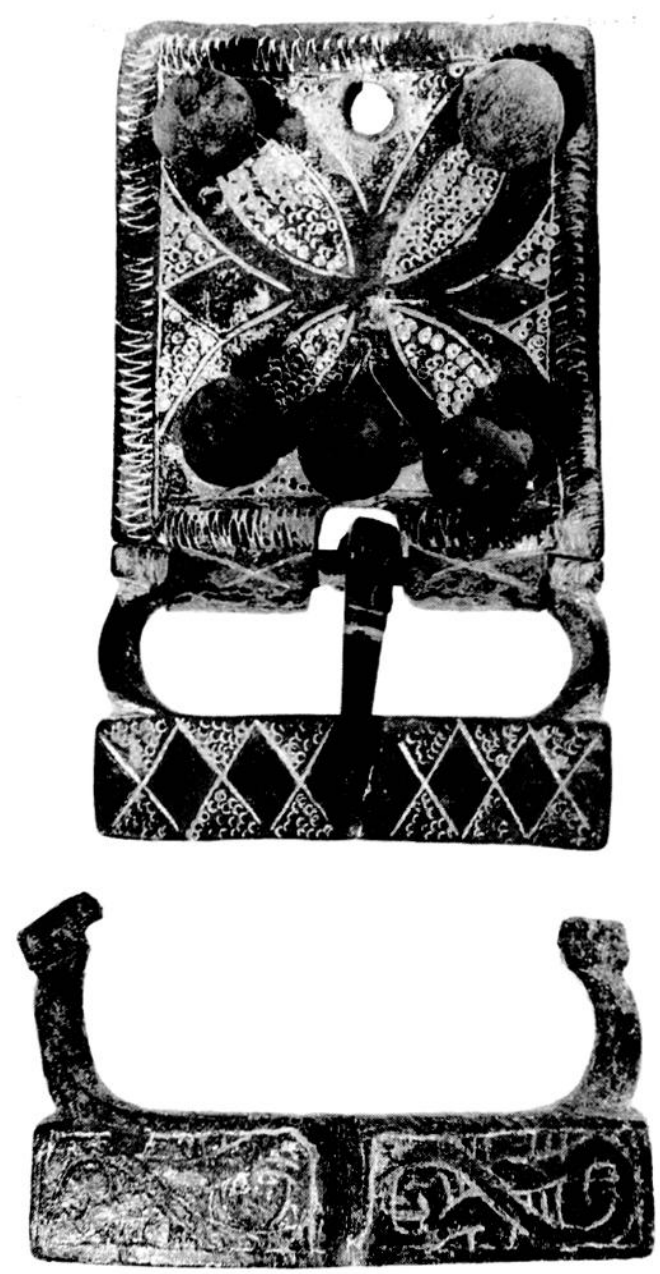

Cliché Y. Rigoir, éch. 1/1. bien caractéristiques des accessoires d'habillement de la fin du XIIIe et du début du XIVe siècle déjà connus en Provence à Rougiers (Démians d'Archimbaud 1981: 483, 494-495, fig. $466 n^{\circ} 1-6$, fig. $463 n^{\circ} 12-14$ ), et notamment en Midi-Pyrénées (Archéologie et vie quotidienne $1990: 208-212$ ).

\section{Bibliographie}

Démians d'Archimbaud 1981 : DEMIANS D'ARCHIMBAUD (G.). - Les fouilles de Rougiers, Contribution à l'archéologie de l'habitat rural médiéval en pays méditerranéen. éd. du C.N.R.S., Paris, 1981, 820 p.

Archéologie et vie quotidienne 1990 : Archéologie et vie quotidienne aux XIIIle et XIVe siècles en MidiPyrénées. Catalogue d'exposition, Musée des Augustins, Toulouse, 1990, $347 \mathrm{p}$. 